\title{
Gastrointestinal symptoms involvement in hospitalised COVID-19 patients in Liverpool, UK: a descriptive cross-sectional, single-centre study
}

\author{
Authors: Gemma Graham, ${ }^{\mathrm{A}}$ Miriam Taegtmeyer, ${ }^{\mathrm{A}}$ Joseph Lewis ${ }^{\mathrm{A}}$ and Sreedhar Subramanian ${ }^{\mathrm{B}}$
}

\begin{tabular}{|c|c|c|c|c|c|}
\hline Variable & $\begin{array}{l}\text { Overall cohort } \\
(n=478)\end{array}$ & $\begin{array}{l}\text { GI symptoms } \\
(n=161)\end{array}$ & $\begin{array}{l}\text { No GI symptoms } \\
(n=317)\end{array}$ & $\begin{array}{l}\text { p value } \\
\text { (chi-squared test) }\end{array}$ & Odds ratio $(95 \% \mathrm{CI})$ \\
\hline Age, median (IQR) & $70(23.0)$ & $68(23.0)$ & $72(22.5)$ & 0.18 & \\
\hline Male, median (IQR) & $279(58.4)$ & $87(54.0)$ & $192(60.6)$ & 0.17 & $0.8(0.5-1.1)$ \\
\hline $\mathrm{BMI} \geq 25, \mathrm{n}$ & 401 & 143 & 258 & & \\
\hline Number ( \%) & $253(63.1)$ & $100(69.9)$ & $153(59.3)$ & 0.04 & $1.6(1.0-2.5)$ \\
\hline Usual residence & & & & $<0.0001$ & \\
\hline Own home - number ( \%) & $309(64.6)$ & $124(77)$ & $185(58.4)$ & & 1.0 Reference group \\
\hline Own home with carers - number ( $\%$ ) & $86(18)$ & $23(14.3)$ & $63(19.9)$ & & $0.5(0.3-0.9)$ \\
\hline Residential home - number ( \% ) & $25(5.2)$ & $5(3.1)$ & $20(6.3)$ & & $0.4(0.1-1.0)$ \\
\hline Nursing home - number ( \%) & $58(12.1)$ & $9(5.6)$ & $49(15.5)$ & & $0.3(0.1-0.6)$ \\
\hline $\begin{array}{l}\text { Clinical frailty score, median (IQR) } \\
\text { [total } n]\end{array}$ & $\begin{array}{l}4(4) \\
{[476]}\end{array}$ & $\begin{array}{l}3(4) \\
{[160]}\end{array}$ & $\begin{array}{l}5(4) \\
{[316]}\end{array}$ & 0.02 & \\
\hline DNAR, number ( \%) & $286(59.8)$ & $80(49.7)$ & $206(65.0)$ & 0.001 & $0.5(0.4-0.8)$ \\
\hline $\begin{array}{l}\text { Community-acquired COVID-19 } \\
\text { ( }<14 \text { days between admission and } \\
\text { positive swab) - number ( } \%)\end{array}$ & $423(88.5)$ & $152(94.4)$ & $271(85.5)$ & 0.004 & $2.9(1.4-6.0)$ \\
\hline
\end{tabular}

\section{Introduction}

Since December 2019, COVID-19 has caused huge global morbidity and mortality. ${ }^{1}$ Although the disease is primarily a respiratory illness, gastrointestinal (GI) symptoms are increasingly recognised. ${ }^{2}$ However, reported literature on the prevalence of these symptoms is conflicting, as is their relationship with disease course and outcome.,

We aimed to identify the prevalence of GI symptoms among a cohort of UK hospitalised adults with confirmed SARS-CoV-2 and to describe the association of GI symptoms with patient characteristics, clinical course and outcome.

Authors: A Liverpool School of Tropical Medicine, Liverpool, UK;

${ }^{B}$ Liverpool University Hospitals NHS Foundation Trust, Liverpool, UK

\section{Materials and methods}

A total of 478 inpatients at the Royal Liverpool University Hospital were retrospectively identified. All patients had a positive SARS-CoV-2 nasopharyngeal swab collected between 23 March and 23 April 2020. Clinical data including demographics, observations, symptoms, investigations and outcomes were extracted from electronic patient records. Variables were compared between those with GI symptoms and those without. Symptom clusters were identified using hierarchical clustering analysis. Multivariate analysis was performed to describe the association of symptoms with mortality. The data were analysed using IBM SPSS Statistics, Version 26.

\section{Results and discussion}

The prevalence of GI symptoms in this cohort was $33.7 \%$ (161/478). Diarrhoea was the most common GI symptom (17.4\%) 
and the fifth most common symptom overall. Other GI symptoms included: anorexia (13.8\%), vomiting (13\%), nausea $(7.5 \%)$ and abdominal pain $(7.3 \%)$. This study identified a respiratory cluster; cough, fever and shortness of breath and a gastrointestinal cluster; diarrhoea, anorexia, nausea, vomiting, abdominal pain, myalgia and headache. $85.1 \%(137 / 161)$ of those with GI symptoms expressed at least one of the three respiratory symptoms.

Overall, the cohort had a median age of 70 and $58.4 \%$ (274/478) were male. There were no significant differences in age and sex between the two symptom groups. Patients with GI symptoms were more likely to have a BMI of $\geq 25$ on univariate analysis (odds ratio (OR) 1.6; 95\% confidence interval (CI) $1.0-2.5 ; \mathrm{p}=0.04$ ). Patients with GI symptoms were more likely to live in their own homes compared with those without GI symptoms and less lived in nursing homes $(\mathrm{p}=<0.0001)$, they had a lower median clinical frailty score ( 3 vs $5, \mathrm{p}=0.02$ ), and fewer had 'do not attempt resuscitation' (DNACPR) status on univariate analysis (OR 0.5; 95\% CI 0.4$0.8 ; \mathrm{p}=0.001)$. More patients presenting with GI symptoms had community-acquired COVID-19 (OR 2.9; 95\% CI 1.4-6.0; $\mathrm{p}=0.004$; Table 1 ).

$10.5 \%$ of patients were admitted to ICU, with no statistically significant difference between the symptom groups. Fewer patients with GI symptoms received oxygen (OR 0.7; 95\% CI $0.4-1.0 ; p=0.045)$. The mortality rate of the cohort was $37.2 \%$ with no statistically significant difference between the symptom groups in multivariate analysis.

\section{Conclusion}

GI symptoms are common in COVID-19 but rarely occur in the absence of respiratory symptoms. Patients with GI symptoms were more likely to be overweight and less frail when compared with those without. GI symptoms are not associated with clinical outcomes from COVID-19. GI symptoms may be underreported in hospital or they may be more relevant to mild COVID-19 within the community that does not require hospitalisation.

\section{Conflicts of interest}

None declared.

\section{References}

1 World Health Organization. Coronavirus disease (COVID-19): Weekly Epidemiological Update. WHO, 2020. www.who.int/docs/ default-source/coronaviruse/situation-reports/20200928-weeklyepi-update.pdf?sfvrsn=9e354665_6 [Accessed 04 October 2020].

2 COVID Symptom Study. The COVID Symptom Study reveals six distinct 'types' of COVID-19. COVID Symptom Study, 2020. https:// covid.joinzoe.com/post/covid-clusters [Accessed 04 October 2020].

3 Tariq R, Saha S, Furqan F et al. Prevalence and mortality of COVID-19 patients with gastrointestinal symptoms: A systematic review and meta-analysis. Mayo Clin Proc 2020;95:1632-48.

4 Tian Y, Rong L, Nian W, He Y. Review article: gastrointestinal features in COVID-19 and the possibility of faecal transmission. Aliment Pharmacol Ther 2020;51:843-51. 